\title{
Nonthermal Plasma Abatement of Trichloroethylene Enhanced by Photocatalysis
}

\author{
Ch. Subrahmanyam, M. Magureanu, ${ }^{\dagger}$ D. Laub, A. Renken, and L. Kiwi-Minsker* \\ Ecole Polytechnique Fédérale de Lausanne, CH-1015 Lausanne, Switzerland \\ Received: October 13, 2006; In Final Form: January 16, 2007
}

\begin{abstract}
Abatement of trichloroethylene (TCE, $250 \mathrm{ppm}$ in air) was studied in a novel nonthermal plasma (NTP) dielectric barrier discharge reactor with an inner electrode made of sintered metal fibers (SMF). The SMF electrodes modified with $\mathrm{TiO}_{2}$ and $\mathrm{MnO}_{2}$ were observed to be catalytically active. Their efficiency in TCE decomposition was compared with a $\mathrm{Cu}$ inner electrode. The SMF electrode modified with $\mathrm{MnO}_{2}$ and $\mathrm{TiO}_{2}$ catalyst effectively destroys TCE due to the synergy between plasma excitation of the TCE molecules and their catalytic oxidation. The latter process was observed to be further enhanced by photocatalysis since $\mathrm{TiO}_{2}$ absorbs the UV light produced by the NTP. These innovative $\mathrm{TiO}_{2}$-modified SMF electrodes were characterized by X-ray photoelectron spectroscopy (XPS) and transmission electron microscopy (TEM), confirming formation of titania anatase, whereas the emission spectrum of the plasma showed the presence of ultraviolet light.
\end{abstract}

\section{Introduction}

Nonthermal plasma (NTP) is able to destroy volatile organic compounds (VOCs) present in gas streams at low concentration with relatively low energy consumption as compared to the conventional thermal and thermocatalytic methods. ${ }^{1-4}$ However, use of the NTP technique is limited due to formation of undesired byproducts like $\mathrm{CO}, \mathrm{O}_{3}$, and $\mathrm{NO}_{x}$ by plasma discharge. A combination of NTP and heterogeneous catalysis increases the efficiency of VOC destruction per unit of energy input. ${ }^{5-9}$ Trichloroethylene (TCE) is a widely used industrial solvent whose abatement by NTP results in formation of undesired products like phosgene, leading to low selectivity toward total oxidation. Nonthermal plasma in air produces ultraviolet (UV) light, mainly due to the radiative transitions of excited nitrogen molecules. ${ }^{10,11}$ Earlier attempts combining NTP with a $\mathrm{TiO}_{2}$ photocatalyst to abate VOCs indicate that the contribution of photocatalysis induced by UV light from the plasma was not significant. ${ }^{12-16}$ Nevertheless, the right positioning of the photocatalyst in the reactor within the discharge is important to efficiently utilize the UV light emitted by the plasma. Recently, we reported a novel dielectric barrier discharge (DBD) reactor provided with the catalytic inner electrode. ${ }^{17,18}$ The catalytic electrode was made of sintered metal fibers (SMF) modified by transition-metal ( $\mathrm{Mn}, \mathrm{Co}$ ) oxides. This reactor shows an improved efficiency during VOCs abatement with higher selectivity toward total oxidation products as compared to the conventional copper $(\mathrm{Cu})$ electrode. ${ }^{17}$ The present study aims at the abatement of TCE using the catalytic NTP reactor with the SMF electrode modified by $\mathrm{TiO}_{2}$ anatase. Synergy is expected between plasma excitation of the reacting molecules and the photocatalytic action of $\mathrm{TiO}_{2}$. The performance was compared with $\mathrm{MnO}_{2} / \mathrm{SMF}$ and $\mathrm{Cu}$ electrodes.

\section{Experimental Section}

The dielectric barrier discharge (DBD) was generated in a cylindrical quartz tube with an inner diameter of $19 \mathrm{~mm}$. The

\footnotetext{
* To whom correspondence should be addressed. E-mail: lioubov. kiwi-minsker@epfl.ch.

$\dagger$ National Institute for Lasers, Plasma and Radiation Physics, Bucharest, Romania.
}

silver paste painted on the outer surface of the quartz tube acts as the outer electrode, and the cylindrical tube of the SMF filter serves as the inner electrode. ${ }^{17}$ The novelty of the DBD nonthermal plasma (NTP) reactor is that the SMF acts as the inner electrode and the catalyst. The discharge length was 10 $\mathrm{cm}$, and the discharge gap was fixed at $1.25 \mathrm{~mm}$. The catalytic SMF electrode was connected to an alternating current (AC) high voltage through a copper rod as shown in Figure 1. The specific input energy (SIE) in the range 140-1100 J/L was varied by changing the amplitude of the AC high voltage (12.5$22.5 \mathrm{kV}$ ) at a constant frequency of $250 \mathrm{~Hz}$. The V-Q Lissajous method was used to determine the discharge power (W) from which the SIE was calculated.

The TCE (250 ppm in air) was introduced into the reactor with a total flow of $0.71(\mathrm{STP}) / \mathrm{min}$ that corresponds to a gas residence time of $2.4 \mathrm{~s}$. The concentration of TCE was monitored with a gas chromatograph (Shimadzu 14 B with a SP-5 capillary column), whereas a gas chromatograph equipped with a mass spectrometer (TRACE DSQ) was used to identify the byproducts formed. An infrared detector (Siemens Ultramat $21 \mathrm{P}$ ) was used to monitor the $\mathrm{CO}$ and $\mathrm{CO}_{2}$ outlet concentration. Ozone formation was measured with an UV absorption detector (API- 450 NEMA). The emission spectrum of the discharge at $20 \mathrm{kV}$ was measured with a SM 240 spectrometer (CVI Spectral Products) with a Sony ILX511 CCD linear array detector.

$\mathrm{TiO}_{2} / \mathrm{SMF}$ and $\mathrm{TiO}_{2} / \mathrm{MnO}_{2} / \mathrm{SMF}$ were prepared by precipitation of Ti(IV) bis(ammonium lactato) dihydroxide, $50 \mathrm{wt} \%$ solution in water at $333 \mathrm{~K}$ for $3 \mathrm{~h}$, whereas $\mathrm{MnO}_{2}$ was deposited by impregnation followed by drying at room temperature and calcination in air at $773 \mathrm{~K}$ for $5 \mathrm{~h} .{ }^{17}$ The $\mathrm{TiO}_{2} / \mathrm{SMF}$ and $\mathrm{MnO}_{2} /$ SMF catalysts contain 3 wt $\%$ of the metal oxide, whereas the $\mathrm{TiO}_{2} / \mathrm{MnO}_{2} / \mathrm{SMF}$ contains 1 and 3 wt $\%$ of $\mathrm{TiO}_{2}$ and $\mathrm{MnO}_{2}$, respectively. XPS analysis confirmed formation of $\mathrm{MnO}_{2}$ on SMF. ${ }^{17}$ The metal-oxide-modified SMF filters were subjected to electrical hot press treatment to obtain the desired cylindrical form. XPS analysis of $\mathrm{TiO}_{2} / \mathrm{SMF}$ was carried out using an Axis Ultra ESCA system (Kratos, Manchester) with monochromatic $\mathrm{Al} \mathrm{K} \alpha$ radiation $(1486.6 \mathrm{eV})$, whereas the TEM images and diffraction patterns were recorded with a Philips CM300UT FEG (300 kV). 


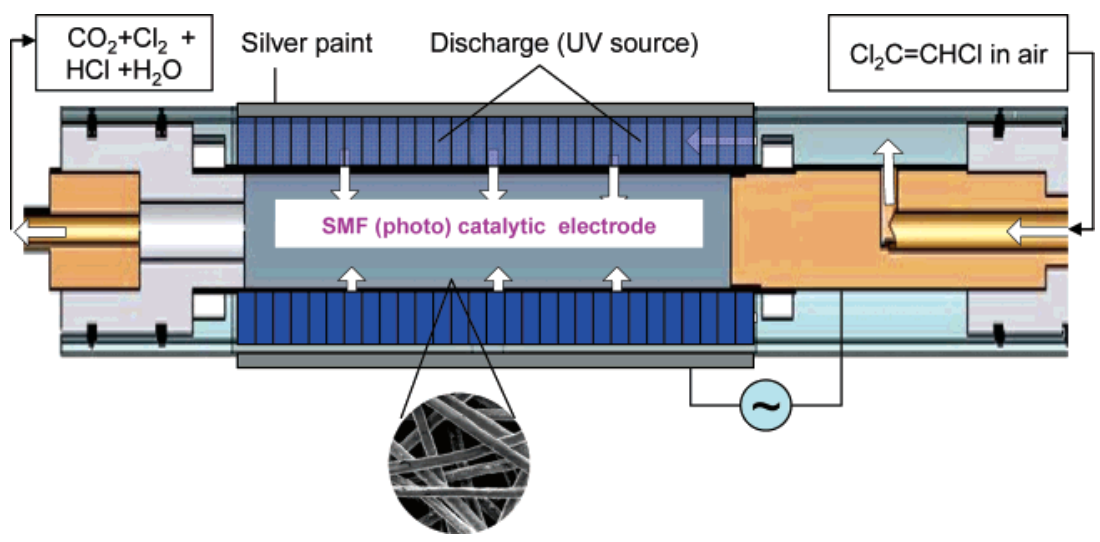

Figure 1. Schematic representation of the DBD plasma catalytic reactor with magnified SMF electrode (SEM image).

\section{Results and Discussion}

The XPS spectrum of $\mathrm{TiO}_{2} / \mathrm{SMF}$ shows two peaks centered at 458.3 and $464 \mathrm{eV}$ corresponding to $\mathrm{Ti} 2 \mathrm{p}_{3 / 2}$ and $2 \mathrm{p}_{1 / 2}$, respectively. Similar peaks were observed for $\mathrm{TiO}_{2} / \mathrm{MnO}_{2} / \mathrm{SMF}$, indicating formation of titania in both cases. This was further supported by TEM studies. Figure $2 \mathrm{a}$ and $\mathrm{b}$ presents TEM images of the $\mathrm{TiO}_{2} / \mathrm{SMF}$ and $\mathrm{TiO}_{2} / \mathrm{MnO}_{2} / \mathrm{SMF}$ catalytic electrodes. The crystallite size in the former sample was $\sim 25 \mathrm{~nm}$, whereas in the later sample the size was $<10 \mathrm{~nm}$. The diffraction pattern of the respective samples is shown in the inset, confirming formation of $\mathrm{TiO}_{2}$ anatase.

During the destruction of TCE with $\mathrm{TiO}_{2} / \mathrm{SMF}$ electrodes, the effect of the UV light can be expected only if NTP emits radiation in the range $\lambda \leq 370-380 \mathrm{~nm}$, which is equivalent to the band gap of anatase $(3.2 \mathrm{eV})$. A typical emission spectrum of the discharge in the wavelength range $250-500 \mathrm{~nm}$ originating from excited species of nitrogen ${ }^{19-21}$ is shown in Figure 3. The high-energy electrons generated in the plasma excite and ionize the nitrogen molecules, leading to the $\mathrm{N}_{2}$ $\left(\mathrm{C}^{3} \Pi_{\mathrm{u}}\right)$ and $\mathrm{N}_{2}{ }^{+}\left(\mathrm{B}^{2} \Sigma_{\mathrm{u}}{ }^{+}\right)$electronic states. De-excitation of these states occurs due to radiative emission and molecular quenching. Hence, decay of the $C^{3} \Pi_{u}$ state to $B^{3} \Pi_{g}\left(N_{2}, C^{3} \Pi_{u}\right.$ $\rightarrow \mathrm{B}^{3} \Pi_{\mathrm{g}}$ ) induces a second positive system (SPS) with the most intense band corresponding to the $(0-0)$ transition at $337 \mathrm{~nm}$. Similarly, decay of the $\mathrm{B}^{2} \Sigma_{\mathrm{u}}{ }^{+}$state toward $\mathrm{X}^{2} \Sigma_{\mathrm{g}}{ }^{+}\left(\mathrm{N}_{2}{ }^{+,} \mathrm{B}^{2} \Sigma_{\mathrm{u}}{ }^{+}\right.$ $\rightarrow \mathrm{X}^{2} \Sigma_{\mathrm{g}}{ }^{+}$) results in the first negative system (FNS) corresponding to the $(0-0)$ transition at $391 \mathrm{~nm} .{ }^{19,20}$ Therefore, emission from excited nitrogen molecules $\left(\mathrm{N}_{2}{ }^{*}\right)$ is in the range of the band gap of the $\mathrm{TiO}_{2}$ catalyst.

The efficiency of the $\mathrm{TiO}_{2} / \mathrm{SMF}$ electrodes was tested during the destruction of TCE (250 ppm in air) as a function of SIE, which was varied in the range $140-1100 \mathrm{~J} / \mathrm{L}$ by varying the voltage $(12.5-22.5 \mathrm{kV})$ at $250 \mathrm{~Hz}$. The results are presented in Figure 4. For comparison, the experiments were also carried out with a copper electrode, which did not show any difference in activity compared to the SMF unmodified electrode. For all the SIE applied, starting from $140 \mathrm{~J} / \mathrm{L}, \sim 100 \%$ conversion of TCE was achieved. However, during the abatement of VOCs, total oxidation is desired. During the present study GC-MS confirms formation of chlorinated byproducts like dichloroacetyl chloride $\left(\mathrm{CHCl}_{2} \mathrm{CClO}, \mathrm{DCAC}\right)$, carbon tetrachloride $\left(\mathrm{CCl}_{4}\right)$, trichloroacetaldehyde $\left(\mathrm{Cl}_{3} \mathrm{C}-\mathrm{CHO}\right.$, TCAA), $\mathrm{Cl}_{2}$, and $\mathrm{HCl}$, but they were not quantified due to the very low concentration. Their removal from the reactor outlet could be done by passing the air steam via a wet scrubber. An interesting observation is that formation of phosgene was not observed. Figure 4 presents the selectivity to the gaseous products $\mathrm{CO}_{x}\left(\mathrm{CO}+\mathrm{CO}_{2}\right)$ formed over SMF electrodes. With the $\mathrm{Cu}$ electrode at $140 \mathrm{~J} / \mathrm{L}$ the

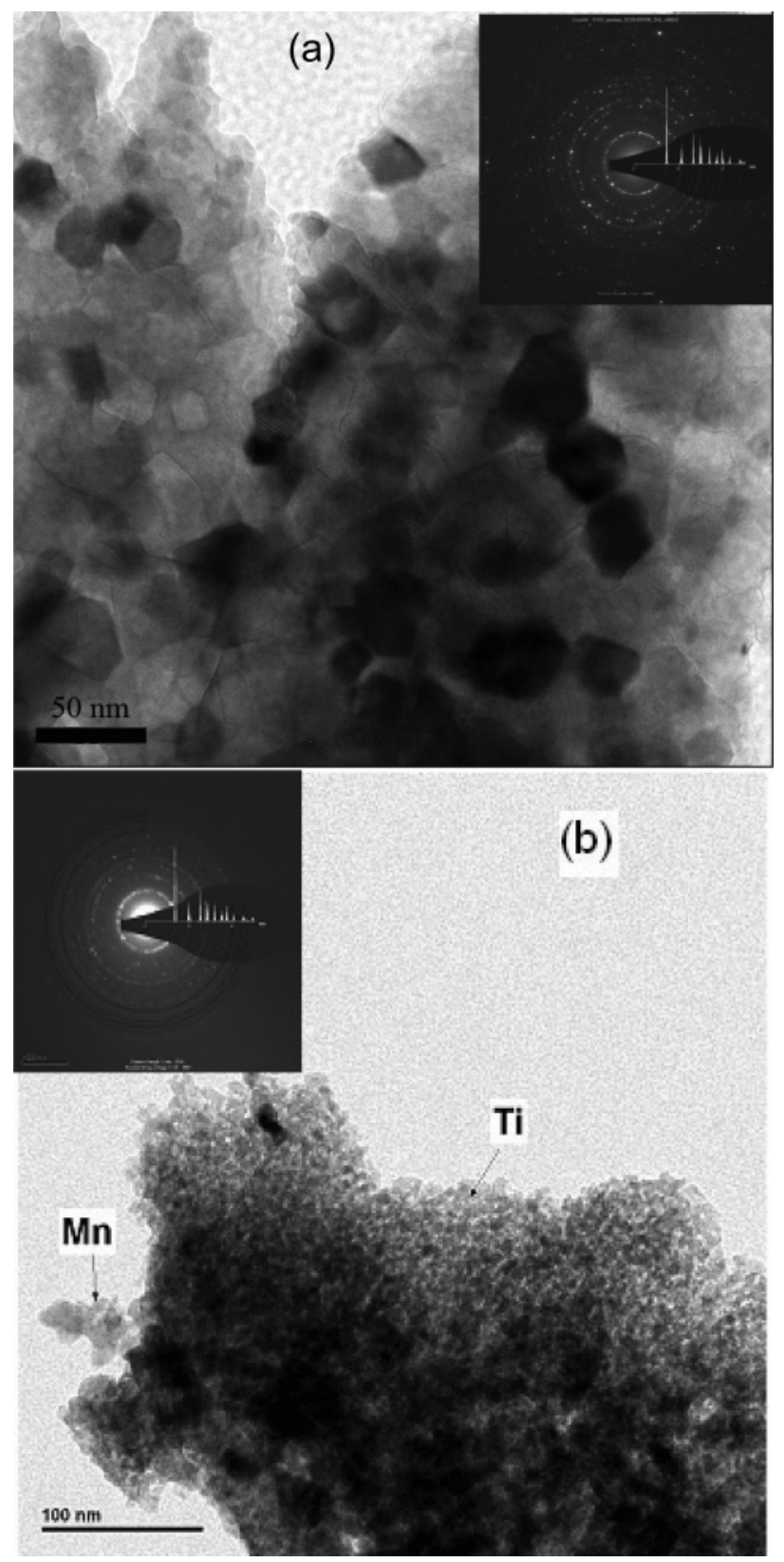

Figure 2. TEM image of (a) $\mathrm{TiO}_{2} / \mathrm{SMF}$ (top) and (b) $\mathrm{TiO}_{2} / \mathrm{MnO}_{2} /$ SMF (bottom).

selectivity observed to $\mathrm{CO}_{x}$ was only $\sim 55 \%$ and $65 \%$ with $\mathrm{TiO}_{2} /$ $\mathrm{MnO}_{2} / \mathrm{SMF}$. With increasing SIE to $830 \mathrm{~J} / \mathrm{L}, \sim 100 \% \mathrm{CO}_{x}$ selectivity was achieved with $\mathrm{TiO}_{2} / \mathrm{MnO}_{2} / \mathrm{SMF}$. 


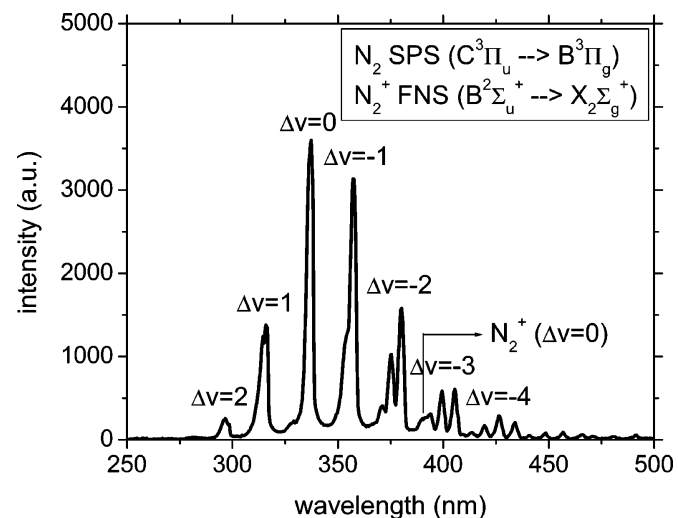

Figure 3. UV-vis emission spectrum of plasma discharge at $20 \mathrm{kV}$.

Figure 4 also presents the selectivity to $\mathrm{CO}_{2}$, showing the effect of metal oxide modification (the effect of catalytic additive). At any SIE the metal-oxide-modified SMF electrodes showed higher $\mathrm{CO}_{2}$ selectivity compared to the $\mathrm{Cu}$ electrode. However, with the $\mathrm{MnO}_{2}$-modified electrode, $\mathrm{CO}_{2}$ selectivity is significantly higher. This may be due to ozone in-situ decomposition on the $\mathrm{MnO}_{2}$ catalyst surface.

To understand the role of ozone in the reaction, its concentration was monitored at the reactor outlet. With the $\mathrm{Cu}$ electrode, at $140 \mathrm{~J} / \mathrm{L}, \sim 1300 \mathrm{ppm}$ of ozone was formed, which decreases with increasing SIE. At $575 \mathrm{~J} / \mathrm{L}(17.5 \mathrm{kV})$, with $\mathrm{Cu}, \mathrm{SMF}$, and $\mathrm{TiO}_{2} / \mathrm{SMF}$ electrodes, $\sim 750 \mathrm{ppm}$ of ozone was formed, whereas with $\mathrm{MnO}_{2}$ and $\mathrm{TiO}_{2} / \mathrm{MnO}_{2} / \mathrm{SMF}$ electrodes no ozone was detected $(\sim 0 \mathrm{ppm})$. This suggests that the observed increased efficiency of the $\mathrm{MnO}_{2} / \mathrm{SMF}$ electrode is due to in-situ decomposition of ozone, which leads to formation of atomic oxygen. ${ }^{1,6,18}$ With the $\mathrm{TiO}_{2} / \mathrm{SMF}$ electrode, the concentration of ozone detected was similar to that obtained with the $\mathrm{Cu}$ electrode $(750 \mathrm{ppm})$. Therefore, the improved performance with $\mathrm{TiO}_{2} / \mathrm{SMF}$ over $\mathrm{Cu}$ cannot be attributed to $\mathrm{O}_{3}$ decomposition on the catalyst. Generally, thermal activation of $\mathrm{TiO}_{2}$ catalyst requires a temperature of $573-673 \mathrm{~K}$, whereas during the present study, the outlet gas temperature never exceeded $\sim 310 \mathrm{~K}$. Optical emission spectroscopy measurements in DBD also confirmed that the gas temperature in the plasma filaments remains close to room temperature. ${ }^{22,23}$ Hence, the better performance of $\mathrm{TiO}_{2} / \mathrm{SMF}$ over $\mathrm{Cu}$ electrode might not be due to thermal activation of $\mathrm{TiO}_{2}$ but rather due to the effect of the UV light coming from NTP. In order to confirm this, $\mathrm{MnO}_{2} /$ SMF was modified with $\mathrm{TiO}_{2}$, and the resulting $\mathrm{TiO}_{2} / \mathrm{MnO}_{2} /$ SMF catalytic electrode at $1100 \mathrm{~J} / \mathrm{L}$ increased $\mathrm{CO}_{2}$ selectivity to $\sim 80 \%$, versus $\sim 65 \%$ with $\mathrm{MnO}_{x} / \mathrm{SMF}$ (Figure 4 ). This synergism is due to a cooperation of oxides having different catalytic functions.

When the $\mathrm{TiO}_{2}$ anatase is irradiated by UV light with energy greater than the band gap $(\sim 3.2 \mathrm{eV}, \lambda \leq 370 \mathrm{~nm})$, excitation of valance-band electrons into the conduction band takes place, resulting in formation of holes in the valance band. Both the holes and the photoelectrons migrate to the $\mathrm{TiO}_{2}$ surface, where they either recombine or participate in redox reactions with adsorbed species like $\mathrm{H}_{2} \mathrm{O}$ and $\mathrm{O}_{2}$. The hole oxidizes adsorbed water to hydroxyl radicals, which are the potential oxidants in photocatalysis, whereas the photoelectrons reduce $\mathrm{O}_{2}$ to superoxide.

The NTP decomposes TCE into several intermediates, which adsorb on the $\mathrm{TiO}_{2}$ surface of the catalytic electrode. These intermediates may then be oxidized by the hydroxyl radicals and superoxide. Under ambient conditions, the titania surface adsorbs water in sufficient quantity to allow the reaction to

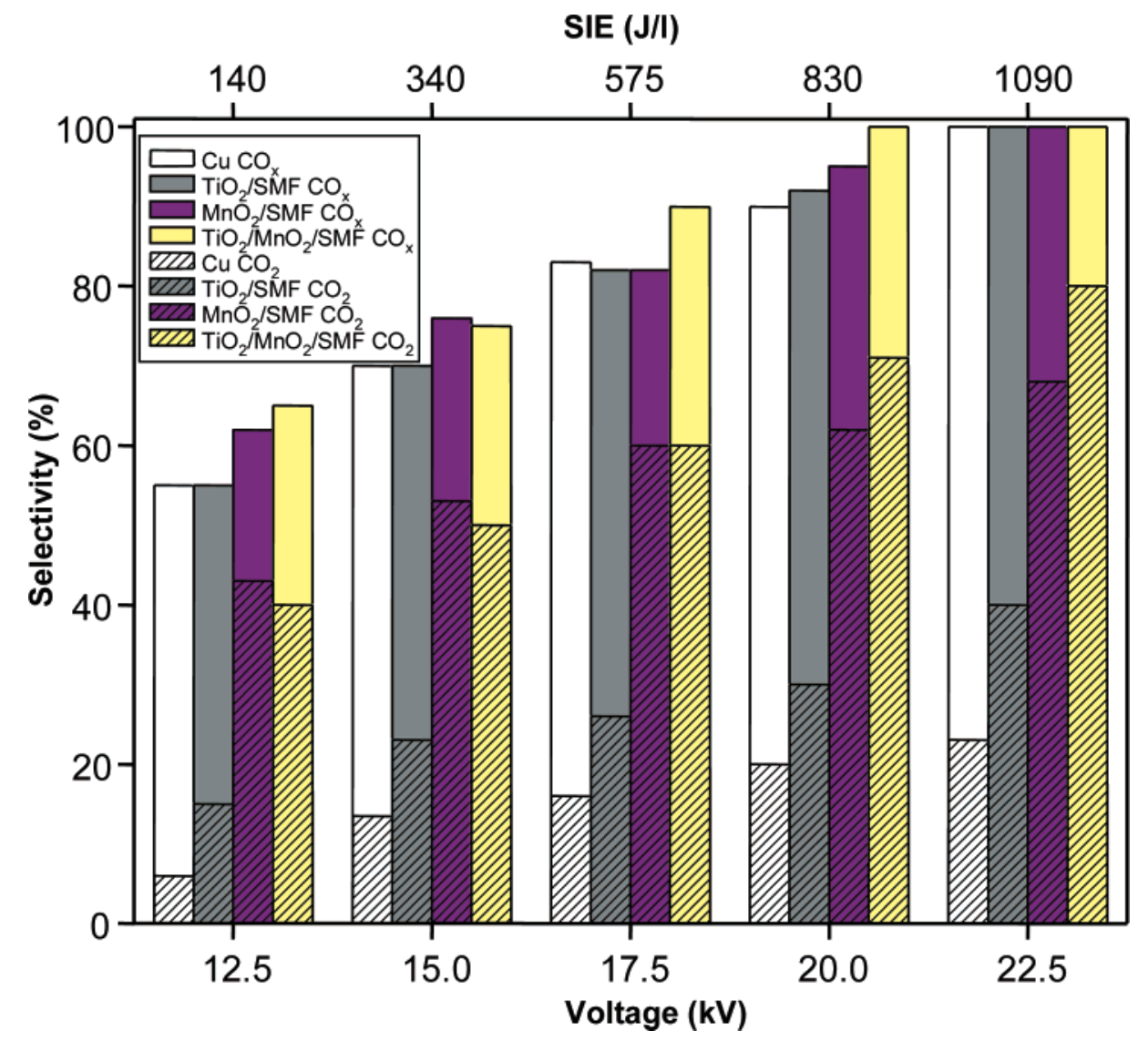

Figure 4. Influence of catalytic electrode modification by $\mathrm{MnO}_{2}$ and $\mathrm{TiO}_{2}$ oxides (the effect of catalytic additive) as a function of specific input energy (SIE) on the selectivity to $\mathrm{CO}_{x}$ and $\mathrm{CO}_{2}(250 \mathrm{ppm}$ of TCE in air, $12.5-22.5 \mathrm{kV}$, and $250 \mathrm{~Hz}$ ); the TCE conversion was $100 \%$. 
proceed. In order to confirm this observation, water was injected $(1 \mathrm{~mL} / \mathrm{h})$ into the DBD reactor; however, a significant difference in the activity was not noticed. Hence, for the destruction of diluted TCE (250 ppm), the $\mathrm{TiO}_{2}$ surface-bound water was sufficient to initiate the reaction, and the $\mathrm{H}_{2} \mathrm{O}$ generated within the TCE oxidation time replenished the $\mathrm{TiO}_{2}$ surface. ${ }^{24-27} \mathrm{~A}$ similar conclusion was reported in an earlier study of the photocatalytic destruction of TCE containing only traces of water. $^{27}$

Several researchers have reported the photocatalytic action of $\mathrm{TiO}_{2}$ anatase during the plasma decomposition of VOCs, supporting the observation made in the present study. ${ }^{20,28-30}$ Interestingly, Ogata et al. observed an improved efficiency of a photoinactive $\mathrm{TiO}_{2}$-rutile catalyst during the destruction of fluorocarbons, which they attributed to the surface oxygen atoms. ${ }^{16}$ Hence, during the present study, contribution of surface oxygen atoms formed by discharge cannot be ruled out. Moreover, the intensity of the light cannot be quantified under the present conditions since the dielectric barrier discharge is a filamentary discharge and not a conventional UV source like an UV lamp. The spectrum was collected by an optical fiber, so the radiation emitted by a number of microdischarges was averaged over both time and space. At the same time, the emission spectrum showed intense bands in the UV region, suggesting photocatalysis over $\mathrm{TiO}_{2}$ anatase. Therefore, the observed increased activity might be due to photocatalytic action in the presence of UV light as well as activation of $\mathrm{TiO}_{2}$ by plasma discharge.

Thermal oxidation of chlorinated VOCs is usually carried out at temperatures $>1000{ }^{\circ} \mathrm{C}$. For catalytic oxidation, a minimum TCE concentration of $1000 \mathrm{ppm}$ is mandatory in order to maintain autothermal conditions. Catalytic destruction of 1000 ppm of TCE was reported over various acidic catalysts like $\mathrm{H}-\mathrm{Y}$ zeolite, $\mathrm{Al}_{2} \mathrm{O}_{3}$, tungasta-alumina, and silica-alumina in the temperature range $400-650^{\circ} \mathrm{C}$ with a selectivity to total oxidation $\approx 50-60 \% .{ }^{31-34}$ Likewise, bimetallic $\mathrm{Cr}-\mathrm{Cu}-$ supported zeolites and $\mathrm{Mn}$-containing perovskites in the temperature range $500-650{ }^{\circ} \mathrm{C}$ showed $\sim 60 \% \mathrm{CO}_{2}$ selectivity with poor carbon balance, giving many undesired byproducts. ${ }^{34-35}$ Hence, there is a need for alternative methods since byproduct formation is unacceptable. During the present study (Figure 4), $\sim 100 \%$ carbon balance toward $\mathrm{CO}_{x}$ formation was achieved with the SIE $\approx 830 \mathrm{~J} / \mathrm{L}$. This supply of energy can heat $1 \mathrm{~L}$ of air up to $\sim 625^{\circ} \mathrm{C}$ in the same temperature range as during the catalytic process. The selectivity of $\sim 70 \%$ to $\mathrm{CO}_{2}$ was achieved with the $\mathrm{TiO}_{2} / \mathrm{MnO}_{2} / \mathrm{SMF}$ catalytic electrode, exceeding the selectivity of the catalytic process. The remaining $\mathrm{CO}$ in the stream is easy to oxidize to $\mathrm{CO}_{2}$ by well-known catalytic converters, which could be put at the outlet after the plasma reactor. It is worth mentioning that $\sim 100 \%$ conversion (complete destruction of TCE) was achieved even at $140 \mathrm{~J} / \mathrm{L}$.

\section{Conclusions}

The DBD nonthermal plasma reactor with a catalytic SMF inner electrode containing both $\mathrm{MnO}_{2}$ and $\mathrm{TiO}_{2}$ catalyst on the surface effectively destroys trichloroethylene, giving $\mathrm{CO}_{x}$ and $\mathrm{H}_{2} \mathrm{O}$. The synergy between plasma excitation of the TCE molecules and their catalytic oxidation was observed to be further enhanced by photocatalysis since $\mathrm{TiO}_{2}$ absorbs the UV light produced by the NTP. Destruction of TCE can be achieved by the NTP technique at lower consumption of energy compared to thermocatalytic methods, but it still needs to be improved in view of achieving total oxidation at low SIE.

Acknowledgment. The authors thank the Swiss National Science Foundation for financial support within the SCOPES program. Technical assistance of Mr. Edy Casali, Mr. Andre Fattet, and Mr. Xanthopoulos at the EPFL is highly appreciated.

\section{References and Notes}

(1) Magureanu, M.; Mandache, N. B.; Eloy, P.; Gaigneaux, E. M.; Parvulescu, V. I. Appl. Catal. B: Environ. 2005, 61, 13.

(2) Holzer, F.; Roland, U.; Kopinke, F. D. Appl. Catal. B: Environ. 2002, 38, 163.

(3) Penetratnte, B.; Hsiao, M. C.; Bardsley, J. N.; Merrit, B. T.; Vogtlin, G. E.; Kuthi, A.; Burkhart, C. P.; Bayless, J. R. Plasma Sources Sci. Technol. 1997, 6, 251.

(4) Yamamoto, T.; Mizuno, K.; Tamori, I.; Ogata, A.; Nifuku, M.; Michalska, M.; Prieto, G. IEEE Trans. Ind. Appl. 1996, 32, 100.

(5) Ogata, A.; Mizuno, K.; Kushiyama, S.; Yamamoto, T. Plasma Chem. Plasma Process. 1999, 19, 383.

(6) Futamura, S.; Einaga, H.; Kabashima, H.; Jwan, L. Y. Catal. Today 2004, 89,89

(7) Kim, H. H.; Oh, S. M.; Ogata, A.; Futamura, S. Appl. Catal. B: Environ. 2005, 56, 213.

(8) Roland, U.; Holzer, F.; Kopinke, F. D. Appl. Catal. B: Environ. 2005, 58, 217.

(9) Roland, U.; Holzer, F.; Kopinke, F. D. Appl. Catal. B: Environ. 2005, 58, 227

(10) Kraus, M.; Eliasson, B.; Kogelschatz, U.; Wokaun, A. Phys. Chem. Chem. Phys. 2001, 81, 294.

(11) Lee, B. Y.; Park, S. H.; Lee, S. C.; Kang, M.; Choung, S. J. Catal. Today 2004, 93-95, 769 .

(12) Futamura, S.; Zhang, A. H.; Yamamoto, T. J. Electrostat. 1997, 42,51

(13) Oda, T.; Yamaji, K.; Takahashi, T. IEEE Trans. Ind. Appl. 2004, $40(2), 430$.

(14) Oda, T.; Takahashi, T.; Yamaji, K. IEEE Trans. Ind. Appl. 2004, $40(5), 1249$.

(15) Sano, T.; Negishi, N.; Sakai, E.; Matsuzawa, S. J. Mol. Catal. A: Chem. 2006, 245, 235.

(16) Ogata, A.; Kim, H. H.; Futamura, S.; Kushiyama, S.; Mizuno, K. Appl. Catal. B: Environ. 2004, 53, 175.

(17) Subrahmanyam, Ch; Magureanu, M.; Renken, A.; Kiwi-Minsker, L. Appl. Catal. B: Environ. 2006, 65, 150.

(18) Subrahmanyam, Ch; Renken, A.; Kiwi-Minsker, L. Appl. Catal. B: Environ. 2006, 65, 157 .

(19) Spyrou, N.; Manassis, C. J. Phys. D: Appl. Phys. 1989, 22, 120 (20) Kim, H. H.; Lee, Y. H.; Ogata, A.; Futamura, S. Catal. Commun. 2003, 4, 347.

(21) Parigger, C.; Plemmons, D. H.; Hornkohl, J. P.; Lewis, J. W. L. Appl. Opt. 1995, 34 (18), 3331.

(22) Eliasson, B.; Kogelschatz, U. IEEE Trans. Plasma Sci. 1991, 19, 1063

(23) Simek, M.; DeBenedictis, S.; Dilecce, G.; Babicky, V.; Clupek, M.; Sunka, P. J. Phys. D: Appl. Phys. 2002, 35, 1981.

(24) Dibble, L. A.; Raupp, G. B. Catal. Lett. 1990,4, 345.

(25) Peral, J.; Ollis, D. F. J. Catal. 1992, 136, 554.

(26) Alberici, R. M.; Jardim, W. F. J. Adv. Oxi. Technol. 1998, 3 (2), 182.

(27) Sitkiwitz, S.; Heller, A. New J. Chem. 1996, 20, 233.

(28) Kang, M.; Kim, B. J.; Cho, S. M.; Chung, C.; Kim, B.; Han, G. Y.; Yoon, K. J. J. Mol. Catal. A: Chem. 2002, 180, 125.

(29) Li, D.; Yakushiji, D.; Kanazawa, S.; Ohkubo, T.; Namoto, Y. J. Electrostat. 2002, 55, 311.

(30) Park, D. W.; Yoon, S. H.; Kim, G. J.; Sekiguchi, H. J. Ind. Eng. Chem. 2002, 18, 393.

(31) Finocchio, E.; Sapienza, G.; Baldi, M.; Busca, G. Appl. Catal. B. Environ. 2004, 51, 143 .

(32) Gutierrez-Ortiz, J. I.; Lopez-Fonseca, R.; Aurrekoetxea, U.; Gonzalez-Velasco, J. R. J. Catal. 2003, 218, 148.

(33) Intriago, L.; Diaz, E.; Ordonez, S.; Vega, A. Microporous Mesoporous Mater. 2006, 91, 161.

(34) Abdullah, A. Z.; Bakar, M. Z. A.; Bhatia, S. J. Hazard. Mater. 2006, B129, 39

(35) Stephan, K.; Hackenberger, M.; Kiessling, D.; Wendt, G. Chem. Eng. Technol. 2002, 25, 5 . 